\title{
Materials Integration Issues for High Performance Fusioh Power Systems
}

\section{Paper ID code: S82-027}

\author{
Dale L. Smith \\ Argonne National Laboratory \\ Fusion Power Program, \\ Technology Development Division \\ 9700 S. Cass Avenue \\ Building 207 \\ Argonne, Illinois 60439 USA \\ Phone: 630-252-4837 \\ Fax: 630-252-5287 \\ e-mail: dalesmith@anl.gov
}




\section{DISCLAIMER}

This report was prepared as an account of work sponsored by an agency of the United States Government. Neither the United States Government nor any agency thereof, nor any of their employees, make any warranty, express or implied, or assumes any legal liability or responsibility for the accuracy, completeness, or usefulness of any information, apparatus, product, or process disclosed, or represents that its use would not infringe privately owned rights. Reference herein to any specific commercial product, process, or service by trade name, trademark, manufacturer, or otherwise does not necessarily constitute or imply its endorsement, recommendation, or favoring by the United States Government or any agency thereof. The views and opinions of authors expressed herein do not necessarily state or reflect those of the United States Government or any agency thereof. 


\section{DISCLAIMER}

Portions of this document may be illegible in electronic image products. Images are produced from the best available original document. 


\title{
Materials Integration Issues for High-Performance Fusion Power Systems*
}

\author{
D.L. Smith, M.C. Billone, S. Majumdar, R.F. Mattas and D.-K. Sze \\ Argonne National Laboratory \\ USA
}

\begin{abstract}
One of the primary requirements for the development of fusion as an energy source is the qualification of materials for the first wall/blanket system that will provide high performance and exhibit favorable safety and environmental features. Both economic competitiveness and the environmental attractiveness of fusion will be strongly influenced by the materials constraints. A key aspect is the development of a compatible combination of materials for the various functions of structure, tritium breeding, coolant, neutron multiplication and other special requirements for a specific system. This paper presents an overview of key materials integration issues for high performance fusion power systems. Issues such as: chemical compatibility of structure and coolant, hydrogen/tritium interactions with the plasma facing/structure/breeder materials, thermomechanical constraints associated with coolant/structure, thermal-hydraulic requirements, and safety/environmental considerations from a systems viewpoint are presented. The major materials interactions for leading blanket concepts are discussed.
\end{abstract}

*Work supported by the U.S. Department of Energy, Office of Fusion Energy, under Contract W-31-109-Eng-38. 


\section{List of Keywords}

C06 Coatings and Coated Particles

B02 Blanket Materials

B04 Breeding Materials

L03 Liquid Metals

Lithium (see Liquid Metals, Breeding Materials, or Metals Alloys and Compounds)

L04 Low Activation and Low Activation Materials (Includes Reduced Activation)

V01 Vanadium, Vanadium Alloys and Compounds

S06 Steels, Ferritic

R03 Radiation Effects: Mechanical Properties

T09 Tritium and Tritides 


\section{Materials Integration Issues for High Performance Fusion Power Systems* D.L. Smith, M.C. Billone, S. Majumdar, R.F. Mattas, and D.-K.Sze}

\section{Introduction}

There are two primary requirements for the development of fusion into a viable energy source. First, it must be economically competitive and second, it must have public acceptance. Decisions regarding the viability of fusion energy will depend on the alternatives and competition for energy generation, and the risk associated with the implementation of a new technology. It is widely recognized that fusion offers a potential for significant safety and environmental advantages as an energy source. However, it is generally concluded that it will be a major challenge to make fusion energy economically competitive. It is also clear that the first-wall/blanket system will have a dominant impact on both the economic and the safety/environmental issues. Since most of the fusion energy is recovered in this system, it will operate at the highest temperature and will be exposed to the highest radiation levels.

Design studies [1-9], including safety and environmental analyses, provide a basis for analysis, evaluation of the potential, comparison of concepts performance, and identification of $R \& D$ priorities. These studies indicate that fusion energy involves high technology and that it will have a high capital cost. This requires that the fusion energy system must have high performance to be economically competitive. It is also recognized that materials limitations pose a primary constraint to the achievement of high performance, since materials for the first wall/blanket system must operate in a highly complex and very demanding environment.

In addition to the high performance requirements of the fusion system, it is important to utilize "low activation" materials in the first wall/blanket system in order to achieve the ultimate safety and environmental advantages of fusion. The products of the deuterium-tritium (D-T) fusion reaction

*Work supported by the U.S. Department of Energy, Office of Fusion Energy, under Contract W31-109-Eng-38. 
are helium, which is environmentally benign, and an energetic neutron, which is needed to react with lithium to breed tritium for the fuel cycle. Therefore, if materials for the in-vessel systems, viz., first wall/blanket, shield, divertor, and auxiliary heating systems, can be constructed of materials that do not produce hazardous isotopes, the attractive features of fusion can be realized.

Therefore, integration of a compatible combination of materials for the nuclear system that provides high performance with attractive safety and environmental features is one of the keys to the successful development of fusion as a viable energy source.

\section{Candidate Materials and Systems.}

The materials requirements for a fusion power system are very complex and highly demanding. Only a limited number of materials for each application, e.g., structure, breeding, cooling, etc., appear to offer a potential to meet even the minimum requirements. In most cases system performance and the safety/environmental attractiveness of fusion will be limited or significantly influenced by the materials constraints. There are no ideal materials for any application but there are several candidate materials which are potentially acceptable that exhibit desirable properties. Table 1 lists the materials considered as leading candidates for each application, viz., structural materials, tritium breeding materials, coolants, neutron multipliers, plasma facing materials and special purpose materials, in a fusion power core. Most of the materials listed in the table exhibit "low activation" characteristics. The compositions of the structural materials are specified such as to maintain low long-term activation properties.

Table 2 lists the blanket concepts, in terms of materials combinations, for the breeder, coolant, structure and neutron multiplier, that are currently considered among the international fusion community to be the leading concepts [2-8]. Also listed are several other options that are currently being evaluated or recently proposed. It is noted that some materials can serve multifunctions, e.g., lithium, PbLi and Flibe can all serve as breeder, coolant and neutron multiplier as well as the tritium recovery processing fluid. 
Three types of materials integration issues must be considered in selecting materials for a high performance system. The first type involves the complex or conflicting requirements for specific candidate materials. An example is the pressure tradeoff for helium coolant. Higher pressure provides for improved heat transfer and a possibility for higher performance; however, higher pressure presents additional safety concerns. Similarly, higher performance may be obtained by operating the structure at higher temperature; however, the strength properties of structural materials typically decrease with increasing temperature, which may impose surface heat flux limitations.

A second type involves materials integration issues within the first-wall/blanket system. Examples of such issues include structure temperature limits imposed by coolant corrosion constraints, or coolant pressure which translates to stress limitations.

Additional materials integration issues arise from potential interactions with other systems. For example, chemical reactivity considerations may preclude the use of water coolant for the divertor because of potential reaction with candidate plasma facing materials on the first wall or liquid metal coolants in the first wall/blanket.

Table 3 is a list of specific materials integration issues that are primary factors in the evaluation of the feasibility, performance limits and safety/environmental attractiveness of the various concepts. Preliminary evaluations of these issues for leading candidate first-wall/blanket systems are discussed in later sections.

\section{Criteria}

Key criteria have generally been defined both for high performance systems, and for safety and environmental issues. The key criteria for high performance systems involve high power conversion efficiency, high wall load capability, reliability for a high availability factor, and long component lifetime. High power conversion efficiency generally relates to higher operating temperatures with an adequate system $\Delta \mathrm{T}$. The higher wall load capability permits higher power density which translates to smaller lower-cost devices. Reliability is more difficult to quantify but is generally related to design simplicity and design margin for the materials and/or system. A long 
component lifetime will minimize scheduled maintenance downtime and typically tends to reduce unscheduled maintenance requirements. Safety criteria can be characterized by normal operating emissions, accidental release issues and waste management issues. Normal operating emissions include primarily tritium and radioactive isotope release during normal operation. Accidental release includes tritium, radioactive isotope and chemical toxicity releases during off-normal events. The waste management criteria involve long-term radioactive material disposal and material recycle considerations.

\section{Performance goals}

Suggested performance goals for an advanced fusion energy system are given in Table 4 . These values are based on US estimates which were derived primarily for a tokamak configuration but are assumed to be generic to magnetic confinement fusion devices [10]. Minimum values represent the minimum acceptable performance parameters while the Goal values are representative of a high performance system.

\section{Design Performance Limits}

Design performance limits for the various materials integration issues listed in Table 3 are predicted in the following section based on available materials properties data, design criteria and currently used design analyses. The primary objective of these analyses is to identify the primary constraints for the various systems and to identify critical R \& D that will provide more precise definition of these constraints.

\subsection{Surface heat flux limits}

Several factors must be considered to define surface heat flux limits for candidate first wall materials. One factor is simply the acceptable operating temperature range for the structural material. Table 5 presents the calculated surface heat flux limits for the three low-activation structural materials, ferritic steel, vanadium alloy and $\mathrm{SiC} / \mathrm{SiC}$ composite for a set of representative design parameters. Based on the representative parameters in Table 5 the first wall heat flux limits for the indicated temperature criteria are $-1.5 \mathrm{MW} / \mathrm{m}^{2}$ for ferritic steel and $2.5 \mathrm{MW} / \mathrm{m}^{2}$ for the vanadium alloy. A key conclusion is the limit for the $\mathrm{SiC} / \mathrm{SiC}$ composite. Although the heat flux 
limit based on unirradiated properties data is very high $\left(4-6 \mathrm{MW} / \mathrm{m}^{2}\right)$, results based on the thermal conductivity of irradiated $\mathrm{SiC} / \mathrm{SiC}[11]$ are well below the suggested minimum values (Table 4). The performance capability of $\mathrm{SiC} / \mathrm{SiC}$ will be severely limited unless composites can be developed in which the thermal conductivity is not degraded to the extent it is in currently available material.

The surface heat flux can also be limited by stress considerations. Figure 1 presents the results of first order heat flux limits based on conventional $\mathrm{S}_{\mathrm{m}}$ analysis for candidate structural materials based only on thermal stress criteria for (unirradiated) ductile materials [8]. Since no primary tensile or creep stress is included for this case, these values represent an upper bound. Values for the vanadium alloy and ferritic steel are higher than those obtained above for the temperature limit criteria. However, values for unirradiated $\mathrm{SiC} / \mathrm{SiC}$ are considerably lower than the limits based only on temperature. These design criteria may also be more questionable for $\mathrm{SiC} / \mathrm{SiC}$ type materials since conventional design rules may not be applicable for these types of materials. The other main observation is the relative strong temperature dependence for the ferritic steel. This strong temperature dependence is also prominent for the thermal creep-rupture data shown in Figure 2. Creep limits may impose additional critical structural temperature constraints, particularly for systems with high pressure coolants.

A plot of heat flux limits based on recent design criteria [12] for a specific set of design parameters (including channel geometry and coolant temperature and pressure) is given for type 316 stainless steel as a function of wall thickness in Figure 3. This analysis illustrates limits based not only on the conventional $S_{m}$ stress criteria but includes stress limits for nonductile material $\left(S_{d}\right)$ such as occurs with Type 316 steel after irradiation, limits imposed by an arbitrary temperature limit $\left(550^{\circ} \mathrm{C}\right.$ in this case), and limits imposed by the Bree criteria (ASME Code). The maximum heat flux limit is determined as a function of wall thickness by following the appropriate set of criteria. For the case shown, the maximum surface heat flux limit is $\sim 0.65 \mathrm{MW} / \mathrm{m}^{2}$ with a wall thickness of $\sim 4.5 \mathrm{~mm}$ (defined by $\mathrm{T}_{\max }$ and Bree curves). If the temperature limit were relaxed, e.g., to $650^{\circ} \mathrm{C}$, the heat flux limit would increase with thickness along the Bree curve until the 
temperature limit was reached $\left(\sim 0.8 \mathrm{MW} / \mathrm{m}^{2}\right.$ at $\sim 6.5 \mathrm{~mm}$ for a ductile material) or to the $S_{\mathrm{d}}$ limit . $\left(\sim 0.72 \mathrm{MW} / \mathrm{m}^{2}\right.$ at $\left.\sim 5.7 \mathrm{~mm}\right)$ if the material is embrittled $\left(\mathrm{E}_{\mathrm{u}}<2 \%\right)$. Sufficient data on the mechanical behavior of the ferritic steels [13] and vanadium alloys are not available to reliably perform the same type of analysis; however, preliminary results obtained on irradiated F82H ferritic steel indicating low uniform elongation (see Figure 4) suggest that the allowable surface heat loads for this material may be constrained by the $S_{d}$ limit. Similar results for vanadium alloys [14] indicate that the allowable surface heat loads for this material may be constrained by the $S_{d}$ limit at temperatures below $430-450^{\circ} \mathrm{C}$ (Figure 4). This type of evaluation cannot be made for $\mathrm{SiC} / \mathrm{SiC}$ at this time. Additional constraints may be imposed by thermal or irradiation-induced creep, cyclic stress effects or possibly high strain rate effects induced by disruptions. Additional data and analysis are required to evaluate those factors.

\subsection{Neutron wall load limits}

Neutron wall load limits will also be imposed by the breeder material or beryllium for some systems because of temperature limits for these materials. The primary constraint results from the impact on tritium breeding which must be maintained above unity to provide for tritium self sufficiency. The example presented here is based on the layered helium-cooled pebble bed (HCPB) blanket design developed in Europe for the DEMO [2-3] and results from the US ARIES studies [15]. For the HCPB design the breeder temperature limits were set at $900^{\circ} \mathrm{C}$ maximum and $350^{\circ} \mathrm{C}$ minimum or a $550^{\circ} \mathrm{C} \Delta \mathrm{T}$. Based on nuclear heating rates, and the thermal conductivity of the solid breeder, the thickness of the breeder zone was calculated to be $11 \mathrm{~mm}$ to maintain the design $\Delta \mathrm{T}$ limit of $550^{\circ} \mathrm{C}$ for the neutron wall load of $2.3 \mathrm{MW} / \mathrm{m}^{2}$. The material distribution within the HCPB blanket, not including the blanket containment structure and coolant volume, was $\sim 60 \%$ Be zone, $16 \%$ breeder zone, and $\sim 24 \%$ structure and coolant. The breeding ratio was calculated to be 1.13. Results obtained from both studies indicate that the maximum neutron wall load for 
ceramic breeder materials based on current materials properties and designs is in the range $2-3 \mathrm{MW} / \mathrm{m}^{2}$, which meets the minimum accepted values but is considerably below the goal values indicated in Table 4.

\subsection{Power conversion efficiency}

The power conversion efficiency depends primarily on the coolant parameters. The estimated power conversion efficiencies for candidate blanket concepts incorporated into the ARIES Reactor Design are summarized in Table 6 along with representative parameters for each system. The net efficiency of the helium-cooled solid breeder concept is limited to $\sim 20 \%$, primarily because of the temperature limit $\left(\sim 520^{\circ} \mathrm{C}\right)$ imposed for the ferritic steel structure and the significant pumping power required for the helium. High temperature helium can provide high power conversion efficiencies as illustrated for the design with a $\mathrm{SiC} / \mathrm{SiC}$ structure $(\sim 40 \%)$. However, there are greater uncertainties associated with the design rules for this type of structure. The water-cooled blanket provides a net efficiency of $\sim 30 \%$, limited primarily by the water coolant. The self-cooled lithium blanket concept also provides a high power conversion efficiency of $\sim 40 \%$. This is also limited primary by the imposed structure temperature limit of $\sim 700^{\circ} \mathrm{C}$ for vanadium alloys.

\subsection{Magnetic interactions}

Two types of magnetic interactions must be considered, viz., magnetohydro-dynamic (MHD) effects associated with a flowing liquid metal and effects associated with a ferromagnetic material (ferritic steel). The MHD interactions will cause a large pressure drop in a flowing system affecting the system pressure and the pumping power requirements. The heat transfer in the coolant will also be degraded since the magnetic field will tend to laminarize the flow. Previous analyses conclude that electrically insulating walls will be required to mitigate the MHD pressure drop for projected liquid metal coolant parameters [16]. Since the dielectric requirements are not severe, the primary solution involves formation of thin, self-healing coatings $(\sim 10 \mu \mathrm{m}$ thick) on coolant channel walls [16-17]. Calcium oxide and aluminum nitride are currently the leading 
candidate coating materials for the $\mathrm{Li} / \mathrm{V}$ system. The effort to date on coating development has been limited and a satisfactory coating has not been demonstrated. However, encouraging results have been obtained with $\mathrm{CaO}$ coatings, which indicate that in-situ formation of coatings on complex shapes, rehealing of defects in the coating, and stability of the coating in lithium all appear feasible. Although consistent results have not been obtained, a thin $(\sim 10 \mu \mathrm{m}) \mathrm{CaO}$ coating on a vanadium alloy provided a resistivity $\sim 5$ orders of magnitude higher than required during a $200 \mathrm{hr}$ exposure to lithium at $\sim 435^{\circ} \mathrm{C}$ [18]. Development of a viable insulator coating is a critical issue for self-cooled liquid metal blankets.

The effects of incorporating a ferromagnetic-material in a magnetic fusion device have not been analyzed in detail. Two issues are of concern, viz., additional mechanical loads induced in the structure and effects of the ferromagnetic material on plasma control. Limited analyses indicate that effects of utilizing ferritic steels in the first wall/blanket system are not prohibitive [19]. However, ferromagnetic materials have not been used in current fusion devices. Primary concerns

relate to nonuniform coverage within the device such as test modules in ITER, effects of disruptions which produce transient magnetic fields, and increased mechanical loads in regions with large magnetic field gradients. It is important to resolve these issues to assure that ferritic steels can be used in a fusion power plant.

\subsection{Hydrogen/Tritium interactions}

Hydrogen and/or tritium interactions can affect both performance and safety/environmental aspects of fusion power. Predominant sources of hydrogen isotopes include the D-T plasma (both energetic and thermalized), tritium breeding in the blanket materials, and hydrogen transmutations in the structure. Key issues include:

- tritium inventory in the structure or plasma facing material from plasma interactions

- tritium inventory in the breeder/multiplier materials from transmutations

- tritium inventory in the structure from the breeder material

- tritium containment within the system 
- hydrogen embrittlement of the structure from transmutations.

Tritium and hydrogen issues do not appear to be a serious problem in the $\mathrm{Li} / \mathrm{V}$ system. Methods for maintaining the tritium concentration in lithium at acceptable levels, i.e., $\sim 1$ appm, appear feasible [20]. The equilibrium hydrogen concentration in vanadium alloys is very low ( -30 appm at $10^{-2} \mathrm{~Pa}$ and $500^{\circ} \mathrm{C}$ ) at hydrogen pressures in the plasma chamber and in lithium [21-22]. Hydrogen generated in vanadium alloys $(\sim 20 \mathrm{appm} / \mathrm{dpa})$ is lower than for other candidate materials. Since hydrogen is highly mobile in vanadium at projected operating temperatures, hydrogen will transfer to either the plasma chamber or the lithium. The insulator coating will tend to limit hydrogen transfer to the lithium; however, preliminary analyses indicate that pathways for removal of hydrogen from the vanadium structure are adequate. This issue is much more critical with other breeding materials ( $\mathrm{PbLi}$, Flibe and solid breeders) which exhibit much higher hydrogen (T) pressures and their use may not be acceptable with vanadium alloys.

For the He/SB/FS/Be blanket concept, the ranges of temperatures for acceptable tritium recovery from the breeder are adequate $[2,8,23-25]$. The relatively high $\mathrm{H}$ pressure in the purge stream is not a problem for the ferritic steel. However, significant build up of tritium in the beryllium ( $2 \mathrm{Kg}$ at $4.4 \mathrm{MW}-\mathrm{y} / \mathrm{m}^{2}$ in HCPB design) [2], is a safety concern. Since the solid breeder system will operate at a relatively high hydrogen/tritium pressure, an oxide tritium barrier is required to reduce tritium permeation to the stream-generator at acceptable levels [2]. The effect of hydrogen generation in the ferritic steel structure ( $45 \mathrm{appm} \mathrm{H/dpa)}$ on the mechanical properties is an important issue, particularly at the lower temperatures. The mobility of hydrogen in ferritic steel is limited at the lower temperatures and transport out to the coolant will be inhibited by the oxide barrier proposed for tritium containment. Critical data on the effects of relatively high hydrogen concentrations on the mechanical properties of ferritic steels are not available.

Tritium recovery from $\mathrm{Pb}-\mathrm{Li}$ in the $\mathrm{H}_{2} \mathrm{O} / \mathrm{PbLi} / \mathrm{FS}$ system appears acceptable; however, the tritium partial pressure in the system will be quite high. Therefore, tritium permeation into the water coolant and tritium containment are major issues. The design solution is a tritium barrier to inhibit permeation into the water $[2,4]$. Significant progress is being made on barrier development 
with an $\mathrm{Al}_{2} \mathrm{O}_{3}$ coating as the leading candidate; however, further development is required to demonstrate adequate barrier performance $[4,26,27]$. The issue of $\mathrm{H}$ transmutation on the mechanical performance of the ferritic steel structure is similar to the previous case. The tritium barriers will tend to inhibit hydrogen transport out of the steel, thus exacerbating the problem.

The hydrogen/tritium issues for the $\mathrm{He} / \mathrm{SB} / \mathrm{SiC} / \mathrm{Be}$ concept are less-well defined. Conventional $\mathrm{SiC} / \mathrm{SiC}$ composites have utilized a carbon bond between the fiber and the matrix. This carbon appears to be a sink for tritium, which requires development of a different bond material. Hydrogen transmutation rates in the $\mathrm{SiC} / \mathrm{SiC}$ are similar to those for the steels. Effects of the very high $\mathrm{He}$ transmutation rate $(\sim 150 \mathrm{appm} / \mathrm{dpa})$ on hydrogen/tritium interactions is not known.

\subsection{Hermiticity}

The issue of hermiticity, particularly inhibiting coolant transport into the plasma chamber, is a critical issue for the high pressure helium coolant. Because of the inherent porosity of $\mathrm{SiC} / \mathrm{SiC}$ composites, hermiticity is a feasibility issue for the $\mathrm{He} / \mathrm{SB} / \mathrm{SiC} / \mathrm{Be}$ system. The proposed design solution is to apply a coating or cladding on the $\mathrm{SiC}$ composite. Monolithic $\mathrm{SiC}$ and metal cladding have been suggested [23]; however, this issue has not been addressed in detail. The concerns relate to the integrity and radiation resistance of the cladding. The issue of hermiticity for the SiC composite is exacerbated by the very high He transmutation rate ( 1600 appm He per MW-y/m ${ }^{2}$. Inhibiting He transport and simultaneously accommodating the high He generation rate appear to be conflicting requirements.

\subsection{Special materials issues}

Several special materials issues are important for the various concepts. Some have been discussed in the previous sections and others are probably yet to be defined. The coating/barrier issues appear to be essential for all concepts, albeit for different reasons. The insulator coating discussed previously is considered a feasibility issue for the $\mathrm{Li} / \mathrm{V}$ system. Tritium barriers, also discussed above, are required for the He cooled systems to avoid excessive tritium permeation into the steam generator, and for the $\mathrm{PbLi}$ breeder to reduce tritium permeation into the water coolant. 
A coating or cladding on $\mathrm{SiC} / \mathrm{SiC}$ is required to maintain hermiticity. Although. satisfactory performance of the insulator coating and the tritium permeation barriers has yet to be demonstrated, preliminary investigations have defined potential solutions with some encouraging results $[20,26$, 27].

Special joining requirements are critical to several systems. Since the $\mathrm{SiC}$ composite is not weldable, some type of braze or bond is required to join this material. The performance and safety/environmental implications associated with a braze have not been evaluated in detail. Similarly brazes or bonds for joining plasma facing materials to the first-wall structure require additional evaluation for the fusion power application, particularly for irradiation effects. Additional evaluation of weldments and weld requirements, e.g., post-weld heat treatment, is important for vanadium alloys and ferritic steels.

\subsection{Safety/Environmental issues}

The safety and environmental issues for fusion will be dominated by the first-wall blanket system and the related materials integration issues. Because of space limitations, the safety and environmental issues are only highlighted here. More comprehensive evaluations are available in the literature [9]. The safety and environmental issues can be characterized according to normal operating emissions, accidental releases, and waste management requirements.

Tritium containment is probably the greatest concern for normal emissions. Lithium is unique among the tritium breeding materials because the tritium partial pressure is many orders of magnitude lower than that for the other candidate materials. Table 7 presents representative values for tritium partial pressure increase per pass of tritium recovery streams for candidate breeding materials. These values represent the minimum tritium pressure in the system for the various blanket systems with the indicated parameters; values will be much higher in practical systems. The tritium partial pressures for $\mathrm{PbLi}$, Flibe and the ceramic breeders (with a He purge stream) are similar. Containment of the tritium at elevated temperatures is an issue for these systems.

Release of radioactivity, chemical reactivity/toxicity, and tritium are the main concerns related to accident scenarios. The primary contributing factors associated with accidental releases include 
system pressure, system complexity, nuclear decay heat, and design margin. The chemical reactivity of lithium with air and water is the dominant issue for the $\mathrm{L} / \mathrm{V}$ system. Favorable characteristics relate to design simplicity since lithium serves as breeder, coolant, neutron multiplier and for tritium recovery; low operating pressure; and low activation (decay heat and long-term activation). The most likely failures for any system are within the vacuum chamber. Since lithium is low pressure and will not react with any of the candidate in-vessel materials, an in-vessel failure should not present a safety issue. Design solutions proposed to mitigate the chemical reactivity problem in the event of an ex-vessel failure involve elimination of water from the reactor room and use of an inert cover gas in the reactor room. This inert cover gas provides additional benefits associated with chemical reactivity of plasma facing materials in the event of a vacuum chamber rupture.

Helium coolant has an advantage of being chemically inert; however, it must be used at high pressure (5-20 MPa). The primary concern relates to the possibility of a vacuum chamber rupture in the event of an in-vessel coolant tube failure for both the $\mathrm{He} / \mathrm{SB} / \mathrm{Be} / \mathrm{FS}$ and the $\mathrm{He} / \mathrm{SB} / \mathrm{SiC} / \mathrm{Be}$ concepts. This effect is more significant since helium is noncondensable. Propagation of a pressure induced rupture could lead to dispersion of the ceramic breeder and beryllium. A second issue relates to potential thermal excursion in the event of a loss of coolant accident. The SiC structure has an advantage over the ferritic steel structure because of the lower decay heat and the higher temperature properties. The chemical reactivity of beryllium is also an issue. Petty [9] has shown that the chemical energy release $\left(\mathrm{GJ} / \mathrm{m}^{3}\right)$ from a water reaction, the $\mathrm{H}_{2}$ release $\left(\mathrm{kg} / \mathrm{m}^{3}\right)$ from a water reaction and the chemical energy release $\left(\mathrm{GJ} / \mathrm{m}^{3}\right)$ from an air reaction with beryllium are approximately one order of magnitude greater than for corresponding reactions with lithium and approximately two orders of magnitude greater than for corresponding reactions with $\mathrm{PbLi}$.

The water coolant presents different safety issues. Water coolant for power producing systems must also operate at high pressures, typically 12-15 MPa. Propagation of pressure induced failures similar to the helium case are of concern; however, water has an advantage in that it will condense on cooling, thus relieving the pressure. Chemical reactions with plasma facing 
materials with hydrogen generation in the event of an in-vessel failure is a major concern. Reaction of water with $\mathrm{PbLi}$ in the $\mathrm{H}_{2} \mathrm{O} / \mathrm{PbLi} / \mathrm{FS}$ concept can also lead to hydrogen generation. Generation of $\mathrm{Po}(210)$ is a major concern with $\mathrm{Pb}$.

Waste management is an important issue for fusion, which is dominated by the materials for the nuclear system. The two primary issues relate to long-term radioactivity and waste disposal requirements, and issues associated with potential for recycle. Activation analysis for the three structural materials ( $\mathrm{V}, \mathrm{FS}, \mathrm{SiC})$, indicate that $\mathrm{SiC}$ has the lowest short term radioactive decay heat and contact dose at short times ( $<10 \mathrm{yr})$, and the vanadium alloy ( $\mathrm{V}-4 \mathrm{Cr}-4 \mathrm{Ti})$ exhibits the lowest long-term decay heat and dose [29-30]. For all three materials the long-term activation is dominated by trace impurities. It is generally concluded that impurities can be controlled at low levels with some economic penalty. A preliminary evaluation indicates that recycle of vanadium is possible [31]. Lithium will not produce activation products except for tritium, which is recovered and used in the fuel cycle. Recycle of lithium involves simply draining and reuse. After extended use, addition of ${ }^{6} \mathrm{Li}$ would be required. Beryllium also produces no long-lived radioactive products except tritium. Recycle of beryllium is considered necessary because of resource limitations. Careful handling will be required because of the tritium and chemical toxicity of beryllium. The $\mathrm{Pb}$ in $\mathrm{PbLi}$ will produce activation products including $\mathrm{Po} 210$ which is a gas. Recycle of $\mathrm{PbLi}$ should be similar to that for $\mathrm{Li}$ with replenishment of $\mathrm{Li}-6$ required periodically. The activation of solid breeder materials depends on which of the $\mathrm{Li}$ ceramics is used, e.g., $\mathrm{Li}_{2} \mathrm{O}$, $\mathrm{Li}_{4} \mathrm{SiO}_{4}, \mathrm{Li}_{2} \mathrm{ZrO}_{3}, \mathrm{Li}_{2} \mathrm{TiO}_{3}, \mathrm{LiALO}_{2}$. Since neither $\mathrm{Li}$ nor oxygen produce long lived radioactive products (assuming $\mathrm{T}$ is recovered), the activation depends on the ternary element. The zirconium is the least desirable and titanium is preferred for low long-term activation. Recycle is generally considered necessary because of the use of highly enriched Li-6. Reprocessing of these ceramics will be considerably more difficult than for the other breeder materials.

\subsection{Reliability}


High reliability of the nuclear system will be essential because of the difficult maintenance for the first-wall/blanket of a fusion system. Reliability is very difficult to evaluate quantitatively, however, qualitative considerations for evaluating reliability include:

- Design complexity including number of materials, number of interfaces (e.g., number of coolant tubes), and configuration

- Design margins for stress and temperature limits

- System pressure which impacts primary stresses

- Number or length of pressure boundary joints or welds

The low pressure systems which employ multifuction materials; e.g., the same material for coolant, breeder, neutron multiplier, should enhance the system reliability.

\section{Summary and conclusions}

Development of a compatible combination of materials for the nuclear system that provides high performance with attractive safety and environmental features is one of the keys to the successful deployment of fusion as a viable energy source. The material requirements for a fusion power system are exceedingly complex and only a limited number of materials offer a potential for high performance. Leading blanket concepts have been identified within the international community and the critical issues and limitations for each concept have been defined. The four concepts which provide the focus for current materials research effort are:

- He-cooled/Solid Breeder/Ferritic Steel structure/Be multiplier (He/SB/FS/Be)

- $\mathrm{Li}$ as coolant, breeder and neutron multiplier/Vanadium alloy structure $(\mathrm{Li} / \mathrm{V})$

- $\mathrm{H}_{2} \mathrm{O}$ coolant/PbLi as Breeder and Multiplier/Ferritic Steel structure $\left(\mathrm{H}_{2} \mathrm{O} / \mathrm{PbLi} / \mathrm{FS}\right)$

- He-cooled/Solid Breeder/SiC Composite structure/Be multiplier (He/SB/SiC/Be)

Key materials integration issues for the $\mathrm{He} / \mathrm{SB} / \mathrm{FS} / \mathrm{Be}$ concept relate to:

- the low power conversion efficiency, which is limited primarily by the ferritic steel temperature constraint 
- the neutron wall load limit for He/FS

- uncertainties associated with the ferromagnetic properties of ferritic steel

- radiation damage, including $\mathrm{He}$ and $\mathrm{H}$ transmutations, on properties of ferritic steel

Key materials integration issues for the $\mathrm{Li} / \mathrm{V}$ concept relate to:

- development of an acceptable insulator coating to mitigate MHD pressure drop

- He and $\mathrm{H}$ transmutation effects on irradiated vanadium alloys

- ability to maintain tritium inventory at acceptable levels

- design to accommodate the chemical reactivity of lithium

Key materials integration issues of the $\mathrm{H}_{2} \mathrm{O} / \mathrm{PbLi} / \mathrm{FS}$ concept relate to:

- development of acceptable tritium barrier to reduce tritium transport into water coolant

- safety associated with pressurized water reactions with $\mathrm{PbLi}$ and plasma facing materials

- the low power conversion efficiency associated with water coolant

- uncertainties associated with the ferromagnetic properties of ferritic steel

- radiation damage, including $\mathrm{He}$ and $\mathrm{H}$ transmutations, on properties of ferritic steel

Key materials integration issues for the $\mathrm{He} / \mathrm{SB} / \mathrm{SiC} / \mathrm{Be}$ concept relate to:

- radiation effects on thermal conductivity of $\mathrm{SiC}$ composite which result in unacceptable low heat flux capability

- development of an acceptable coating or cladding to provide adequate hermiticity

- development of acceptable joining methods that can withstand the projected fusion environment

- radiation damage, including the high $\mathrm{He}$ transmutations rates, on the properties of the $\mathrm{SiC}$ composite

- development of design codes relevant to composite materials for fusion applications

High priority R\&D issues which are Generic to all concepts include:

- evaluation of transmutation effects, primarily $\mathrm{He}$ and $\mathrm{H} / \mathrm{T}$, on properties of irradiated materials and tritium inventory

- development of coatings or claddings which appear essential for all concepts 
- Continue detailed design studies to provide a basis for system evaluation and comparison, and prioritization of $R \& D$ 


\section{REFERENCES}

1. D.L. Smith, et al., Fusion Technol. 8, No. 1, (1985) 10.

2. L. Giancarli, et al., Fusion Engr. \& Design 27A (1995) 337.

3. M. Dalle Donne, "Development of EU Helium-Cooled Pebble Bed Blanket," Fusion Engr. \& Design (in press).

4. L. Giancarli, et al., "Development of EU Water-Cooled Pb-17Li Blanket," Fusion Engr. \& Design (in press).

5. H. Takatsu, et al., "Development of Ceramic Breeder Blankets in Japan," Fusion Engr. \& Design (in press).

6. I. R. Kirillov, et al., "Liquid Lithium Self-Cooled Breeding Blanket Design," Fusion Engr. \& Design, (in press).

7. D.K. Sze, et al., "The ARIES-RS Power Core-Recent Developments in Li/V Design," Fusion Engr. \& Design (in press).

8. R. F. Mattas and M.C. Billone, J. Nucl. Mater., 233-237 (1996) 72.

9. D.A. Petti, et al., J. Nucl. Mater., 233-237 (1996) 37.

10. M. Saltmarsh, et al., Final Report of the Advanced Technologies/Materials Working Group (unpublished). 
11. L.L. Snead, et al., J. Nucl. Mater., 233-237, (1996) 26.

12. S. Majumadar and P. Smith, "Treatment of Irradiation Effects in Structural Design Criteria for Fusion Reactors," Fusion Engr. \& Design (in press).

13. A. Kohyma et al., J. Nucl. Mater. 212-215 (1994) 684

14. D.L. Smith et al., "Progress in Data from the Vanadim Alloy Development for Fusion Applications," Fusion Engr. \& Design (in press).

15. D. K. Sze, personal communication, (1997).

16. T. Q. Hua and.Y. Gohar, Fusion Engr. \& Design, 27 (1995) 696.

17. C.C. Baker, et al., "Tokomak Power Systems Study," ANL/FPP-085-2, Argonne National Laboratory, (1985).

18. J.H. Park and T. F. Kassner, J. Nucl. Mater., 233-237, (1996) 476.

19. H. Attaya, et al., J. Nucl. Mater., 122-123 (1984) 96.

20. D.K. Sze, et al., "Tritium Processing System for the ITER Li/V Blanket Test Module," Fusion Engr. \& Design (in press).

21. J.H. Park, et al., Fusion Materials Semi-Annual Progress Report, December 31, 1995, DOE/ER-0313/16 (1994) p. 50. 
22. J.H. DeVan, et al., Fusion Materials Semi-Annual Progress Report, March 31, 1994, DOE/ER-0313/16 (1994) p. 240.

23. M.C. Billone, J. Nucl. Mater., pp. 233-237 (1996) 1462.

24. N. Roux, et al., Fusion Engr \& Design, 27 (1995) 154.

25. J.G. van der Laan, et al., "Analysis of Performance Data from Ceramic Breeder Irradiation Experiments," Fusion Engr. \& Design (in press).

26. T. Terai, et al., "Research and Development of Ceramic Coatings for Fusion Reactor Liquid Blankets," Fusion Engr. \& Design (in press).

27. A. Perujo, et al., "The Development of Tritium Permeation Barriers for Blankets," Fusion Engr. \& Design, (in press).

28. R. Jones, et al., "Development of $\mathrm{SiC} / \mathrm{SiC}$ as a Fusion Structural Material," Fusion Engr. \& Design (in press).

29. H. Attaya and D. Smith, J. Nucl. Mater., 191-194, (1992) 1464.

30. D. Smith, et al., Fusion Engr. \& Design, 27C (1995) 399.

31. G.J. Butterworth, et al., J. Nucl. Mater., 212-215 (1994) 667. 
Table 1. Prmary Candidate Materials Considered For The First Wall Blanket System Of A Fusion Power System.

\begin{tabular}{|c|c|c|c|c|c|}
\hline \multicolumn{3}{|c|}{ Tritium } & \multicolumn{3}{|c|}{ Plasma } \\
\hline Structure & Breeding & & Neutron & Facing & Other \\
\hline Materials & Materials & Coolant & Multiplier & Materials & Materials \\
\hline Vanadium Alloys & Lithium & $\mathrm{Li}$ & $\mathrm{Be}$ & $\mathrm{Be}$ & T-Barriers \\
\hline Ferritic Steels & $\mathrm{Pb}-\mathrm{Li}$ & $\mathrm{He}$ & $\mathrm{Pb}$ & C & Insulator Coatings \\
\hline $\mathrm{SiC} / \mathrm{SiC}$ & $\begin{array}{l}\mathrm{Li}-\mathrm{Ceramic} \\
\left(\mathrm{Li}_{2} \mathrm{ZrO}_{3}, \mathrm{Li}_{2} \mathrm{TiO}_{3}, \text { etc. }\right)\end{array}$ & $\begin{array}{l}\mathrm{H}_{2} \mathrm{O} \\
\text { Flibe }\end{array}$ & $\mathrm{Li}$ & $\begin{array}{l}\text { W } \\
\text { Structural }\end{array}$ & $\begin{array}{l}\text { Insulating Ceramics } \\
\text { He-Barriers }\end{array}$ \\
\hline Copper Alloys & Flibe & & & Materials & Corrosion Barriers \\
\hline
\end{tabular}


Table 2. Blanket Concepts Currently Being Evaluated Or Recently Proposed

[(Breeder/Coolant/Structure/Neutron Multiplier (NM)]

\section{Leading concepts}

$\mathrm{Li}-$ Ceramic $/ \mathrm{He} / \mathrm{FS} / \mathrm{Be}$

$\mathrm{Li} / \mathrm{V}$

$\mathrm{PbLi} / \mathrm{H}_{2} \mathrm{O} / \mathrm{FS}$

$\mathrm{Li}$-Ceramic/ $\mathrm{H}_{2} \mathrm{O} / \mathrm{FS} / \mathrm{BE}$

Other options under consideration

Flibe/FS

$\mathrm{PbLi} / \mathrm{He} / \mathrm{FS}$

$\mathrm{Li} / \mathrm{He} / \mathrm{V}$

$\mathrm{Li}-\mathrm{Ceramis} / \mathrm{He} / \mathrm{SiC} / \mathrm{Be}$
He purge for T-Recovery

Li serves as Breeder/Coolant/NM and for T-Recovery

$\mathrm{PbLi}$ serves as Breeder/NM and for T-Recovery

He purge for T-Recovery

Flibe serves as Breeder/coolant/NM and for T-Recovery

PbLi serves as Breeder/Blanket Coolant/ NM and for T-Recovery: He cooled FW

Li serves as Breeder/NM and for T-Recovery

He purge for T-Recovery 
Table 3. Material Integration Issues For A High Performace Fusion First-Wall Blanket System.

-Neutron Wall Load and Surface Heat Flux Limits

-High Power Conversion Efficiency

-Neutronic Effects including Tritium Breeding and Nuclear Transmutations

-Electromagnetic Effects

- Environmental and Safety Considerations

-Hydrogen (Tritium) Interactions including Tritium inventory and containment

- Coolant Pressure and Hermeticity Considerations

- Chemical Compatibility and Corrosion/Mass Transfer

-Special Materials Requirements such as Insulator Coatings and Tritium Barriers

- System Reliability 
Table 4. Suggested Performance Goals for A High Performance Fusion Energy System

\section{Criteria}

Average Neutron Wall Load (MW/m²)

Peak Heat Flux Capability (MW/m²)

High Heat Flux Components

First Wall

First Wall Lifetime (MW $\mathrm{y} / \mathrm{m}^{2}$ )

(dpa)

Average Cost of Core Materials $(\$ / \mathrm{Kg})$

Net Cycle Efficiency (\%)
Minimum

Values

Goal

Values

2-3

5-10

$5-7$

$1-1.5$

50

$2-4$

10

$\sim 100$

20

$\sim 200$

$\sim 100$

$\sim 50$

$-40$

$>50$ 
Table 5. Surface Heat Flux Limit for Candidate Structural Materials Based on Estimated Temperature Limits

Structural Material

Maximum Temperature, ${ }^{\circ} \mathrm{C}$

Maximum Coolant System $\Delta \mathrm{T},{ }^{\circ} \mathrm{C}$

Maximum First Wall $\Delta \mathrm{T},{ }^{\circ} \mathrm{C}^{*}$

Heat Flux Limit $\left(\mathrm{MW} / \mathrm{m}^{2}\right)^{* *}$

$5 \mathrm{~mm}$ thick wall

$3 \mathrm{~mm}$ thick wall

* Assumed maximum wall $\Delta T$

${ }^{* *}$ Values based on data for existing materials

\section{Ferritic \\ Steel}

550

250

200

1.2

1.9
Vanadium
Alloy

750

350

300

2.0

3.2
$\mathrm{SiC} / \mathrm{SiC}$

Composite

950

450

400

4.0 (unirrad)

0.4 (irrad)

6.4 (unirrad)

0.6 (irrad) 
Table 6. Estimated power conversion efficiencies for candidate blanket concepts

\begin{tabular}{|c|c|c|c|c|}
\hline Concept & $\mathrm{He} / \mathrm{SB} / \mathrm{FS} / \mathrm{Be}$ & $\mathrm{H}_{2} \mathrm{O} / \mathrm{PbLi} / \mathrm{FS}$ & $\mathbf{L i} / \mathbf{V}$ & $\mathrm{He} / \mathrm{SB} / \mathrm{SiC} / \mathrm{Be}^{* *}$ \\
\hline Coolant & $\mathrm{He}$ & $\mathrm{H}_{2} \mathrm{O}$ & $\mathrm{Li}$ & $\mathrm{He}$ \\
\hline Coolant Pressure (MPa) & 8 & 15 & 0.4 & 15 \\
\hline $\mathrm{T}_{\mathrm{in}},{ }^{\circ} \mathrm{C}$ & 250 & 265 & 330 & 350 \\
\hline $\mathrm{T}_{\text {out }}{ }^{\circ} \mathrm{C}$ & 450 & 325 & 610 & 650 \\
\hline Approx. Gross Efficiency (\%) & 28 & 35 & 46 & 49 \\
\hline Approx. Net Plant Efficiency (\%) & 19 & 28 & 39 & 39 \\
\hline
\end{tabular}


Table 7. Tritium Parameters for Candidate Tritium Breeder/materials.

\begin{tabular}{llll} 
& Flow rate, g/s* & $\Delta$ c/pass, appb & $\Delta$ p/pass, Pa \\
\hline $\mathrm{Li}$ & $3.6 \times 10^{6}$ & 3.36 & $2.6 \times 10^{-13}$ \\
$\mathrm{LiPb}$ & $8.0 \times 10^{7}$ & 3.75 & 0.15 \\
Flibe & $6.3 \times 10^{6}$ & 27.4 & 5.5 \\
He/Solid breeder & & & $5.5^{* *}$ \\
\hline
\end{tabular}

*Flow rate for self-cooled system

***Tritium pressure in the purge 


\section{List of Figures}

Figure 1 Heat Flux/Temperature

Figure 2 Thermal Creep Strength

Figure 3 Stainless Steel First Wall, $5 \mathrm{~mm}$ Thick Back Wall $10 \mathrm{~mm}$ Wide by $20 \mathrm{~mm}$ High Coolant Channel

Figure 4 Irradiation $\mathrm{T},{ }^{\circ} \mathrm{C}$ 


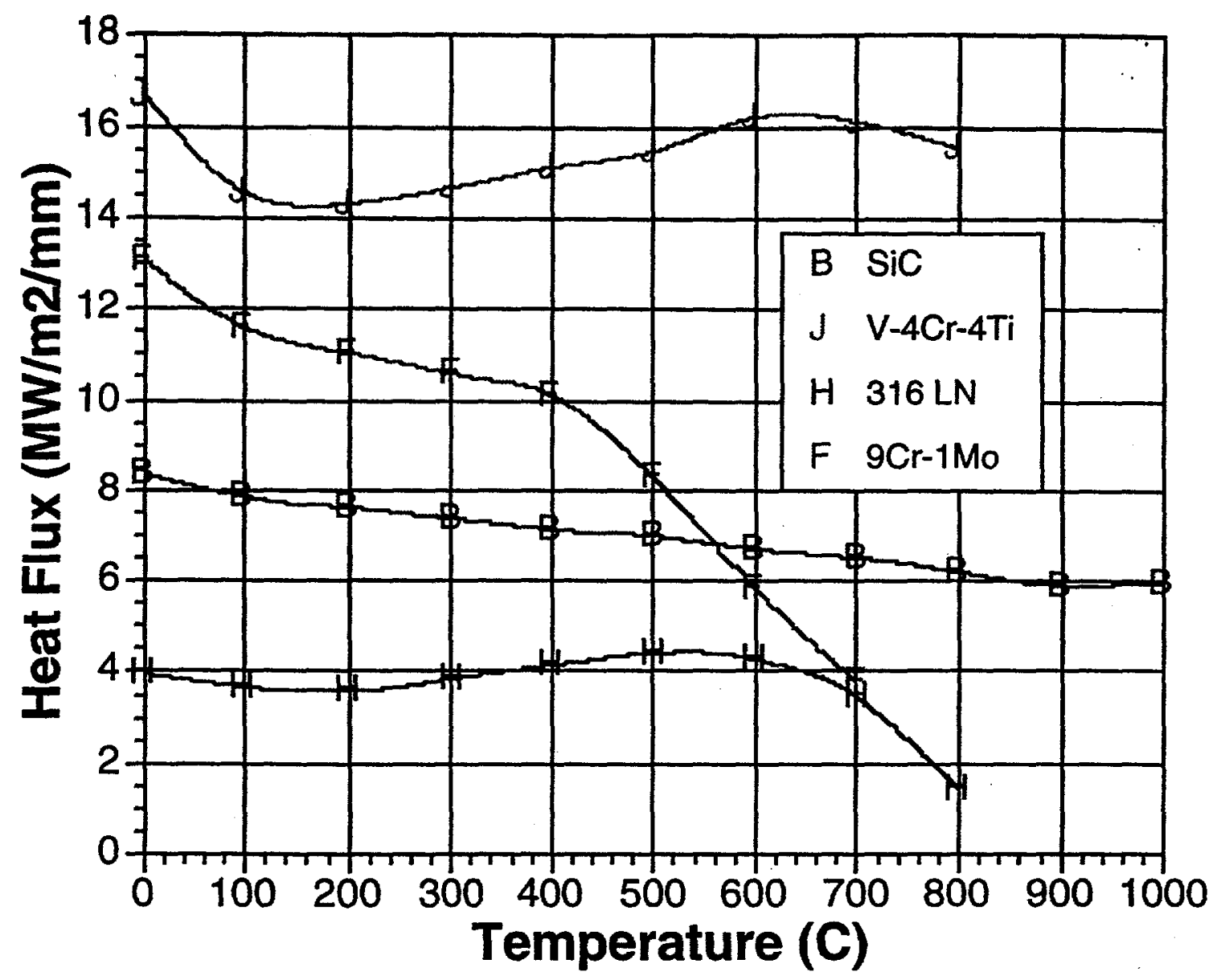

Figure 1. Heat flux limit based on $S_{m}$ for candidate structureal materials 


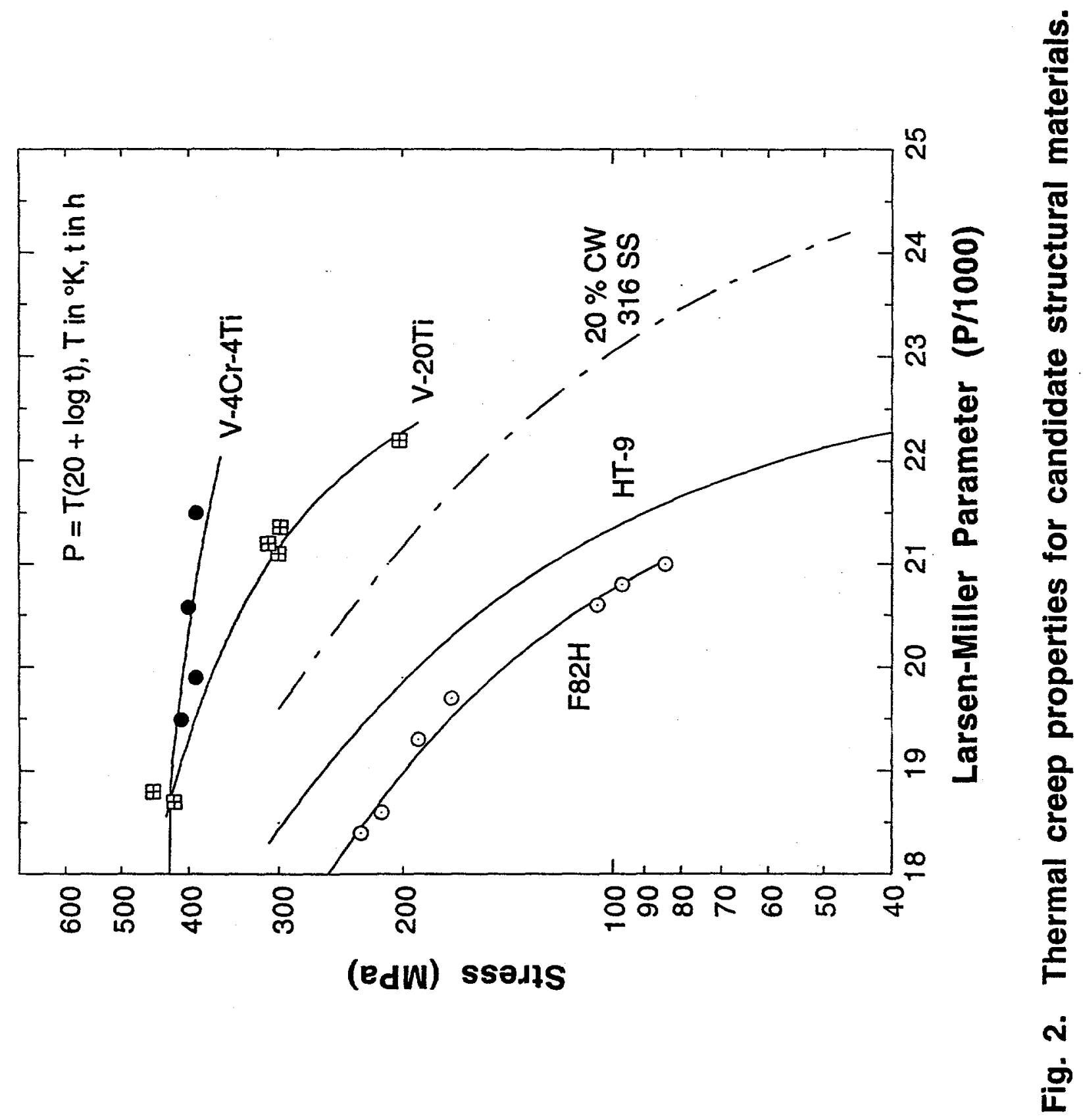


Stainless Steel First Wall, $5 \mathrm{~mm}$ Thick Back Wall $10 \mathrm{~mm}$ Wide by $20 \mathrm{~mm}$ High Coolant Channel

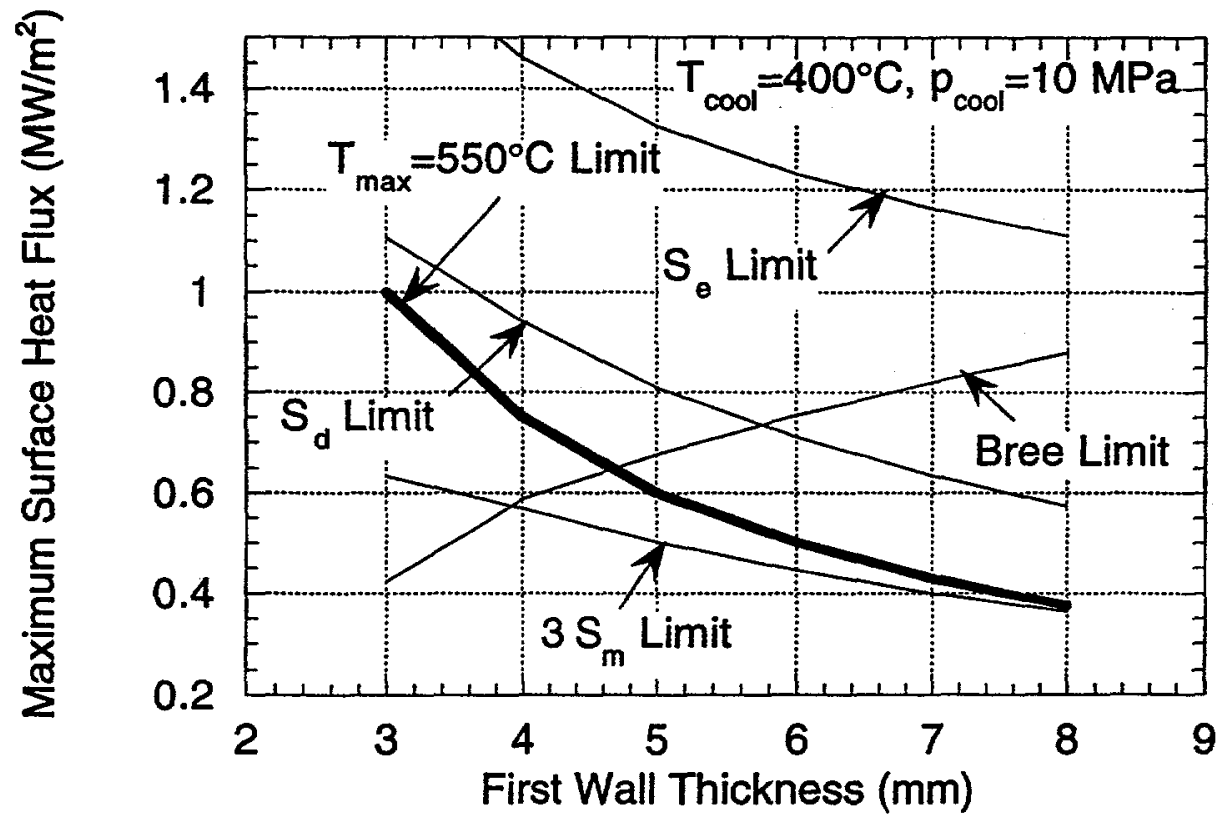

Fig. 3. Calculated surface heat flux limits as function of wall thickness for representative parameters for an austenitic steel wall. 


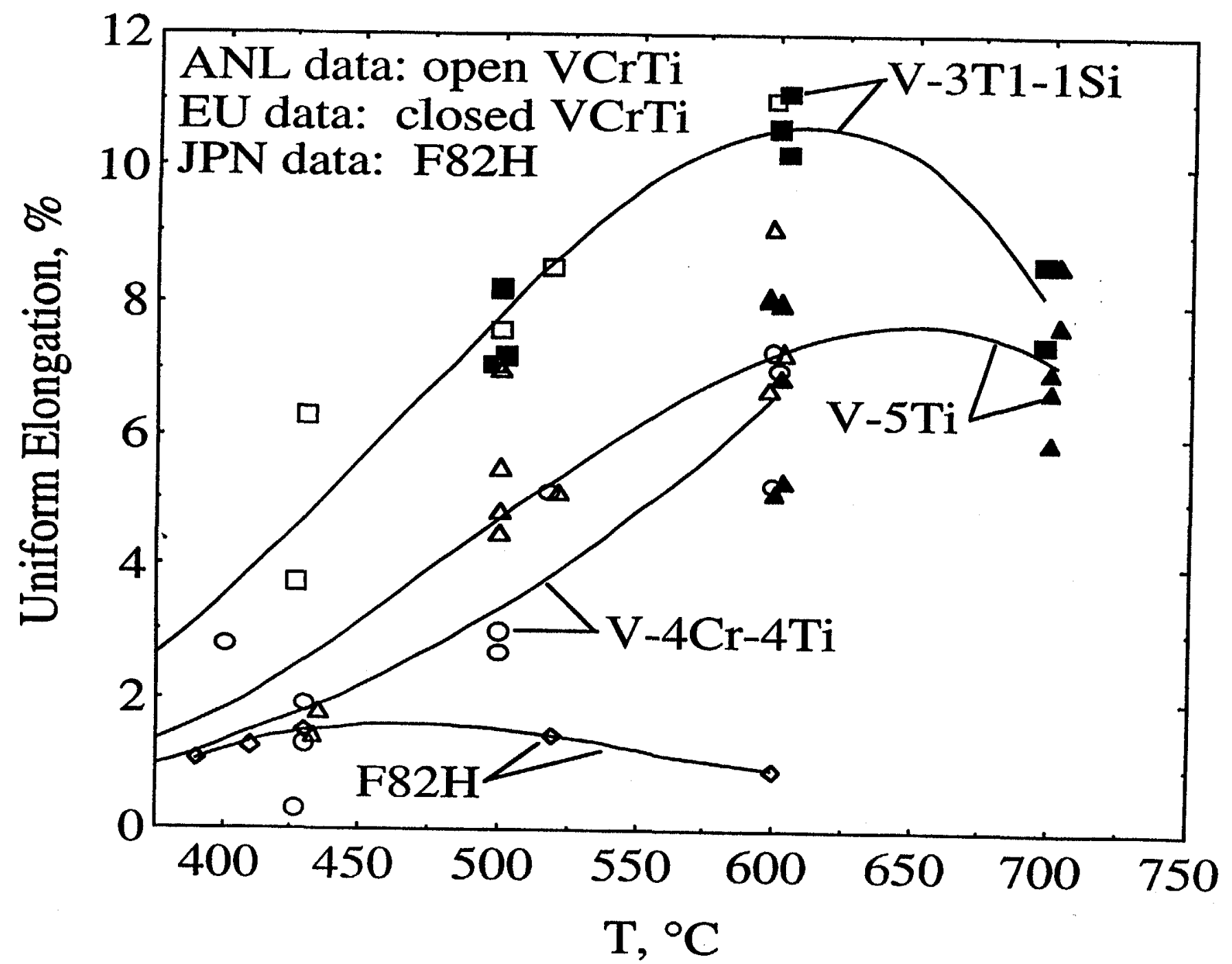

Figure 4. Uniform elongation of irradiated (6-33 dpa) vanadium alloys compared to irradiated ( $-36 \mathrm{dpa}) \mathrm{F82H}$ (test temperature $\approx$ irradiation temperature). 